\title{
Editorial: Climate Change and Anthropogenic Impacts on Soil Organic Matter
}

\author{
Meng Yang You ${ }^{1}$, Xiao Jun Allen $\mathrm{Liu}^{2}$ and Lu-Jun $\mathrm{Li}^{1,3 *}$ \\ ${ }^{1}$ Key Laboratory of Mollisols Agroecology, Northeast Institute of Geography and Agroecology, Chinese Academy of Sciences, \\ Harbin, China, ${ }^{2}$ Institute for Environmental Genomics and Department of Microbiology and Plant Biology, University of Oklahoma, \\ Norman, OK, United States, ${ }^{3}$ College of Advanced Agricultural Sciences, University of Chinese Academy of Sciences, Beijing, \\ China
}

Keywords: climate change, soil organic matter, peatland, soil respiration rate, biochar, urbanization, carbon neutrality

\section{Editorial on the Research Topic}

\section{Climate Change and Anthropogenic Impacts on Soil Organic Matter}

Soil organic matter (SOM) is the largest terrestrial carbon (C) pool and is a critical component in affecting soil quality and global C cycling (Schlesinger and Bernhardt, 2013). The changes of SOM characteristics due to variable vegetation under different ecosystems (e.g., peatland, dryland) around cold and temperate regions affect $\mathrm{C}$ input and sequestration, resulting in $\mathrm{CO}_{2}$ sink or source variety (Yu et al., 2013; Wang et al., 2020). The interactions of soil and vegetation have complex influences on soil $\mathrm{C}$ sequestration, and their responses to global climate change remain elusive. In recent years, the changing climate, such as warming, elevated atmospheric $\mathrm{CO}_{2}$ concentration, nitrogen deposition, and changes in precipitation, have altered the rates of SOM decomposition and biogeochemical processes, possibly modifying anthropogenic impacts on the $\mathrm{C}$ cycle (Balogh et al., 2016; Field et al., 2017; Kuzyakov et al., 2019). Besides, climate change and anthropogenic activities have altered terrestrial ecosystem structures and functions (Chen et al., 2021). However, the mechanism of the $\mathrm{C}$ cycle is still unclear. Accordingly, examining the critical indicators between environmental change and anthropogenic activities will help understand soil functions under future climate change.

Information on these topics refer to climate change and anthropogenic activities on $\mathrm{C}$ cycle will help better understand how human activities affect soil quality and advance our capacity to more accurately predict soil $\mathrm{C}$ feedbacks to the atmosphere under environmental change. Four original research articles have been published on this topic.

As a unique terrestrial ecosystem in cold regions, permafrost is sensitive to climate change, while climate warming has caused rapid permafrost degradation and promoted the decomposition of SOM. Liu et al. explore the response of soil enzymes activities to permafrost degradation and their relationships with soil $\mathrm{C}, \mathrm{N}$, and $\mathrm{P}$ by selecting three types of permafrost regions to simulate permafrost degradation. The study demonstrated that permafrost degradation in peatland might affect soil enzyme activities by changing soil physicochemical properties during the freezing and thawing process, and the enzyme activities could be used as an effective indicator for evaluating the function of peatlands in permafrost ecosystems.

Reductions in precipitation induced by climate change can greatly impact terrestrial $\mathrm{C}$ cycling. Shen et al. evaluated the effect of decreased precipitation on soil respiration rates, including heterotrophic and autotrophic components, by carrying out an experiment comprising of three precipitation manipulation treatments in a semiarid shrubland ecosystem. The authors found that precipitation exclusion significantly depressed soil heterotrophic and autotrophic respiration and 
decreased the contribution of heterotrophic respiration to soil total respiration. The study helps to predict possible changes between $\mathrm{C}$ loss and storage in semiarid shrublands under climate change.

Biochar has been suggested as a promising strategy to enhance soil $\mathrm{C}$ sequestration and mitigate climate change. Understanding the SOM mineralization in response to biochar amendments is crucial for mitigating the greenhouse gas emission and optimizing the climatic impacts of forest ecosystems. Lu et al. examine the effect of ${ }^{13} \mathrm{C}$ labeled biochar on SOM mineralization and microbial community structure at a higher incubation temperature than the average annual temperature. The study showed that the biochar prepared at higher temperature decreased the turnover of native SOM and presented a positive effect on soil $\mathrm{C}$ sequestration. The soil microbial community structure was only affected by biochar pyrolysis temperature. These findings indicate that biochar amendment under climate warming can be important to improve soil quality and develop sustainable forest ecosystems.

Urbanization is another essential factor that affects SOM decomposition; for example, soils with impervious surfaces in the urban area encounter soil sealing and compaction, which will

\section{REFERENCES}

Balogh, J., Papp, M., Pintér, K., Fóti, S., Posta, K., Eugster, W., et al. (2016). Autotrophic Component of Soil Respiration Is Repressed by Drought More Than the Heterotrophic One in Dry Grasslands. Biogeosciences. 13, 5171-5182. doi:10.5194/bg-13-5171-2016

Chen, Y., Feng, X., Tian, H., Wu, X., Gao, Z., Feng, Y., et al. (2021). Accelerated Increase in Vegetation Carbon Sequestration in China After 2010: A Turning Point Resulting From Climate and Human Interaction. Glob. Change Biol. 27, 5848-5864. doi:10.1111/gcb.15854

Field, C. D., Evans, C. D., Dise, N. B., Hall, J. R., and Caporn, S. J. M. (2017). LongTerm Nitrogen Deposition Increases Heathland Carbon Sequestration. Sci. Total Environ. 592, 426-435. doi:10.1016/j.scitotenv.2017.03.059

Kuzyakov, Y., Horwath, W. R., Dorodnikov, M., and Blagodatskaya, E. (2019). Review and Synthesis of the Effects of Elevated Atmospheric CO2 on Soil Processes: No Changes in Pools, but Increased Fluxes and Accelerated Cycles. Soil Biol. Biochem. 128, 66-78. doi:10.1016/j.soilbio.2018.10.005

Schlesinger, W. H., and Bernhardt, E. S. (2013). Biogeochemistry: An Analysis of Global Change. third ed. Waltham, MA: Academic Press.

Wang, S., Zhang, Y., Ju, W., Chen, J. M., Ciais, P., Cescatti, A., et al. (2020). Recent Global Decline of CO 2 Fertilization Effects on Vegetation Photosynthesis. Science. 370, 1295-1300. doi:10.1126/science.abb7772 influence the dynamic of SOM. However, questions remain regarding whether and how expanding impervious surface areas under global urbanization may alter soil waterextractable organic matter (WEOM) cycling. Wang et al. report that WEOM was depleted after long-term coverage of impervious surface as expected. Moreover, the microbial-humiclike and protein-like fluorescent WEOM persisted more dominantly than the terrestrial-humic-like and nonfluorescent WEOM, suggesting that biogeochemical processes in soils are possibly maintained preferentially in the form of WEOM over other SOM components.

We hope this Research Topic will help increase understanding and improve evaluation of the "carbon neutrality" in different ecosystems and regions and boost readers' research interest in SOM dynamics and biogeochemical cycling in response to climate change.

\section{AUTHOR CONTRIBUTIONS}

All authors listed have made a substantial, direct, and intellectual contribution to the work and approved it for publication.

Yu, G.-R., Zhu, X.-J., Fu, Y.-L., He, H.-L., Wang, Q.-F., Wen, X.-F., et al. (2013). Spatial Patterns and Climate Drivers of Carbon Fluxes in Terrestrial Ecosystems of China. Glob. Change Biol. 19, 798-810. doi:10.1111/ gcb. 12079

Conflict of Interest: The authors declare that the research was conducted in the absence of any commercial or financial relationships that could be construed as a potential conflict of interest.

Publisher's Note: All claims expressed in this article are solely those of the authors and do not necessarily represent those of their affiliated organizations, or those of the publisher, the editors and the reviewers. Any product that may be evaluated in this article, or claim that may be made by its manufacturer, is not guaranteed or endorsed by the publisher.

Copyright (C) 2021 You, Allen Liu and Li. This is an open-access article distributed under the terms of the Creative Commons Attribution License (CC BY). The use, distribution or reproduction in other forums is permitted, provided the original author(s) and the copyright owner(s) are credited and that the original publication in this journal is cited, in accordance with accepted academic practice. No use, distribution or reproduction is permitted which does not comply with these terms. 